\title{
EL ENSAYO SOBRE LAS OPINIONES POLÍTICAS EN ESPAÑA DE ANTONIO ESCUDERO (1837), O EL AN- TICLERICALISMO RABIOSO DE UN LIBERAL TIBIO
}

\author{
Aline Vauchelle
}

En diciembre de 1837 salió a la luz, en la imprenta parisina de Moessard, una obra en octavo de 55 páginas titulada Ensayo sobre las opiniones políticas en Espa$\tilde{n} a$. Se puso en venta en la prestigiosa librería de Galignani ${ }^{1}$, creada en 1801 y que, además de despachar libros en francés, proponía -y sigue proponiendo- un amplio surtido de obras en lenguas extranjeras, señaladamente en inglés. Al parecer, esta edición parisina es la única que se realizó de dicho libro, firmado por Antonio Escudero y que no se publicó en España, ni fue traducido al francés². Por desgracia, debido a las lagunas que afectan a los registros del Depósito Legal a partir de mediados de los años 30, desconocemos el número de ejemplares de la tirada.

Según los pocos datos que hemos podido recoger acerca de su autor, Antonio Escudero nació en Sevilla en 1813, donde desempeñaba el cargo de Relator de la Audiencia 3 . Pese a lo que podría sugerir a primera vista el título, su Ensayo... no es un análisis imparcial de la situación política de su país, sino que es una obra nítidamente beligerante en contra del carlismo. Lo escribió Escudero en un momento en que la guerra civil se encontraba en un punto álgido, cuando

1. VAuChelle, Aline, Les ouvrages en langue espagnole publiés en France au temps de la première guerre carliste,1834-1840, Publications de l'Université de Provence, 2003, p. 158.

2. Palau y Dulcet, Antonio, Manual del librero hispanoamericano, Barcelona, 1948, 2. a ed.; Catalogue des ouvrages imprimés de la Bibliothèque Nationale de France.

3. Enciclopedia Universal Ilustrada Europeo-americana, Madrid, Espasa-Calpe, 1958; EscudERo y Perosso, Francisco, Tipografía hispalense. Anales bibliográficos de la ciudad de Sevilla desde el establecimiento de la imprenta hasta fines del siglo XVIII, Madrid, Establecimiento tipogáfico «Sucesores de Rivadeneyra», 1894. 
las tropas del pretendiente estaban en las puertas Madrid, después de ocupar Segovia en agosto. Unas circunstancias, pues, en las que apremiaba acabar con la división entre los dos bandos antagónicos del liberalismo, moderados por un lado y progresistas por otro, para luchar con mayor eficacia contra la amenaza carlista. Dicha reconciliación entre los liberales fue uno de los propósitos perseguidos por el Gobierno progresista de José María Calatrava, al impulsar la elaboración de una nueva Constitución, que se promulgó el 18 de junio de 1837. Este gabinete, con Mendizábal como titular de Hacienda, se había formado en agosto de 1836, después de que el motín de los sargentos de La Granja obligara a la regente María Cristina a restablecer la Constitución de 1812, mucho más democrática que el Estatuto Real otorgado en 1834, y democrática con exceso a juicio de los moderados.

Por ende, a pesar de ser redactada bajo los auspicios de los progresistas, la nueva Carta Magna fue un texto de compromiso. Reanudando con el principio rector del Código gaditano, se reconocía la soberanía de la nación, pero, al mismo tiempo, se atribuían a la Corona amplias facultades en materia legislativa, en especial el derecho de veto ilimitado y la prerrogativa de disolver el Congreso de los Diputados. Se mantenía el bicameralismo, instituido por el Estatuto Real, aunque, en adelante, sendas cámaras, el Congreso y el Senado, disfrutarían de facultades legislativas iguales. No obstante, los senadores seguían siendo nombrados por la Corona, mientras los diputados seguían siendo elegidos por sufragio censitario. Y, por mucho que la nueva ley electoral rebajaba los requisitos de fortuna para ejercer el derecho de voto, el electorado no superaba el 2,2\% de la población masculina (250.000 ciudadanos), quedando convenido que las clases propietarias y los sectores más preeminentes de la burguesía eran los únicos en tener el discernimiento necesario para elegir a sus representantes. Por lo menos, en el título primero, constaba una declaración de derechos, en la que se reconocía la libertad de imprenta, sin censura previa. A la postre, mucho más allá de «revisar la Constitución de Cádiz», según afirmaba el Preámbulo del nuevo pacto, los progresistas abandonaron la mayor parte de los principios de 1812 y se acercaron a los del liberalismo moderado a la sazón imperante en distintos países europeos y, particularmente, a las ideas del doctrinarismo francés. Por eso mismo, los liberales más radicales denunciaron este texto constitucional como una traición al «Código Sagrado» de Cádiz y se orientaron hacia el republicanismo.

Cabal prueba de que esta Constitución fue un texto de transacción es que Escudero, quien es liberal, pero dista mucho de ser un progresista, se adhiere a ella sin reserva.

En su Ensayo..., antes de dar cuenta de las ideologías que se enfrentan y provocan el desastre que está asolando su patria, dedica mucho más espacio a 
recorrer la Historia de España. Ello se debe, sin duda, al historicismo tradicional, pero también a la voluntad de nuestro autor de evidenciar las raíces de los infortunios que ésta padece. Y, en buena lógica, su estudio no es nada ecuánime.

Empieza declarando, no sin cierto énfasis, que España ha sido el teatro de los sucesos que más han influido en los destinos de Europa durante veinte siglos ${ }^{4} \mathrm{y}$ que en la actualidad es la arena en que se arrastran los dos principios que dividen al mundo civilizado. Por consiguiente, la guerra que está haciendo estragos en España concierne a toda Europa. Así, nuestro ensayista nos proporciona, de entrada, una aclaración sobre los motivos por los que fue en Francia donde se publicó su texto: allí esperaba encontrar una caja de resonancia, con vistas a persuadir a los gobiernos liberales europeos, singularmente Francia e Inglaterra, a que facilitasen un auxilio firme al ministerio español en la lucha anticarlista. Hay que reconocer que, si bien tanto Luis Felipe como el gabinete whig de lord Charles Grey se mostraron muy favorables a la consolidación de un régimen liberal moderado en España y apoyaron la causa de la joven reina Isabel II frente a las pretensiones dinásticas de su tío don Carlos, en rigor bien poco hicieron sobre el terreno. Inglaterra se contentó con mandar una legión, mientras el «rey ciudadano», después de mucho andar con rodeos, acabó denegando el concurso militar de Francia y se limitó a aportar una ayuda financiera al Gobierno español, así como a autorizar el reclutamiento de voluntarios liberales en el territorio francés. Sin embargo, a juicio de Escudero, Europa no puede desentenderse de lo que está en juego en España, como quiera que forman parte integrante de la misma civilización cristiana y la evolución, o la revolución, de las opiniones en un país, enseguida se transmite a sus vecinos ${ }^{5}$.

Después de este preámbulo, nuestro autor se remonta precisamente a los orígenes de la civilización europea, para presentar un balance de la implantación del cristianismo en Europa. Gracias a la conversión de los pueblos germánicos, acabaron las devastaciones bárbaras y el triunfo de esta religión apacible y bondadosa permitió erradicar el principio del privilegio del conquistador, que se sustentaba en la fuerza, sustituyéndolo por el derecho y la igualdad evangélica ${ }^{6}$. Pero las cosas pronto se torcieron, y olvidándose los ministros del altar de su sagrada misión, se dejaron seducir por el afán de lucro y de poder, llevando, además, una vida escandalosa, poco conforme con la pureza del cristianismo prístino:

4. Escudero, Antonio, Ensayo sobre las opiniones políticas en España, París, Imprenta de Moessard, 1837, (Signatura Biblioteca Nacional de Francia: Oc 1139), p. 1.

5. Ibid., p. 2.

6. Ibid., p. 3. 
«Los ministros del altar, cediendo al atractivo del poder y la riqueza, y descuidando la misión civilizadora y espiritual a que eran llamados, se secularizaron en el sentido lato de la expresión; se dejaron ganar por el feudalismo, se hicieron señores feudales; así es que el obispo, que el abad mitrado hacía la guerra, cazaba, tenía su séquito marcial de siervos y de hombres de armas, sus mujeres y sus concubinas ».

De ahí que en el siglo XI el papa Gregorio VII reformara la Iglesia. Con todo, al mismo tiempo, este Sumo Pontífice asentó su autoridad en el poder temporal, convirtiendo a Europa en una «teocracia, administrada por sus lugartenientes, los reyes $\aleph^{8}$. Por lo tanto, en opinión de Escudero -quien parece olvidarse de que el Estado estuvo sometido a la potencia de la Iglesia desde que el cristianismo se volvió religión oficial, o sea ya en tiempos de Teodosio, a fines del siglo IV-, el pontificado de Gregorio estuvo en el origen de lo que él llama «el principio teocrático» y al que achaca la responsabilidad de todos los males que han aquejado su patria desde hace siglos. La Iglesia desertó entonces de la causa del pueblo y de la igualdad, imponiendo su hegemonía mediante el abuso. Concretamente, en España dicho «principio teocrático» se fortaleció con la Reconquista, que favoreció el «influjo deletéreo del ascendiente monacal y las injerencias de la corte romana» en los asuntos temporales 9 .

Luego, con los Habsburgos se acentuó todavía más ese dominio clerical, al paso que el país estuvo sometido a la tiranía de Carlos I, príncipe extranjero que, reprimiendo con un baño de sangre a las Comunidades de Castilla y suprimiendo la libre reunión de representantes a Cortes, desterró la libertad política y anonadó cualquier posibilidad de buen gobierno y de progreso ${ }^{10}$. Escudero se refiere aquí a una teoría, formulada en tiempos de la Ilustración y que más tarde hicieron suya los liberales, a cuyo tenor, antes de la entronización de los Austrias, existía en España una tradición democrática que se remontaba al medioevo y cuyo parangón era el reino de Aragón, en el que el soberano no podía prescindir del asentimiento de las Cortes para promulgar una ley. En realidad, Claude Morange y Gérard Dufour han demostrado cómo la supuesta democracia aragonesa no pasaba de ser quimérica ${ }^{11}$. Fue un espejismo al que acudieron los liberales

7. Ibid., p. 4.

8. Ibid., p. 5.

9. Ibid., p. 6 .

10. Ibid., p. 7

11. Morange, Claude, «El conde de Montijo. Reflexiones en torno al «partido» aragonés aristocrático de 1794 a 1814», Trienio, Ilustración y liberalismo, Madrid, 4 (noviembre 1984), p. 35; Dufour, Gérard, «El tema de la constitución antigua de Aragón en el pensamiento político de la Ilustración española», en Actas del I Symposium del Seminario de Ilustración Aragonesa, Zaragoza, 1987, pp. 215-222. 
para legitimar su revolución, inscribiéndola en una antigua tradición nacional de lucha contra el despotismo.

Prosigue Escudero denunciando los estragos cometidos por el «principio teocrático» durante el reinado de Felipe II, quien encabezó la cruzada promovida por «el espiritu invasor» de Roma «contra la inteligencia humana y el cristianismo puro»-la Reforma luterana-. Lo que se plasmó en el apogeo de la Inquisición y del monaquismo, provocando el divorcio completo entre España y la Europa civilizada por más de dos siglos ${ }^{12}$. España quedó sumida en una larga noche de tinieblas, mientras otros países europeos progresaban a pasos agigantados, gracias a la Reforma y al desarrollo de la prensa, así como al descubrimiento del Cabo de Buena Esperanza, que dio un considerable impulso al comercio, a la industria y a la navegación. A su vez, todos estos factores posibilitaron la aproximación de los pueblos, la comunicación de ideas, la reflexión acerca de los derechos y deberes de los gobernantes y gobernados, la consideración del trabajo, el origen del bienestar de las naciones, el influjo de la clase media en la Administración pública en Inglaterra y, en fin, la filosofía del siglo XVIII ${ }^{13}$. Sobre esta filosofía de las Luces, Escudero emite un juicio bastante matizado: le reconoce el eminente mérito de haber proclamado «verdades eternas en politica y en moral», sin embargo le reprocha su dogmatismo y su soberbia, amén de no pocos extravíos. Es más, hace hincapié en que dichas «verdades eternas» de las que se enorgullece la filosofía dieciochesca, ya las había enunciado y legado a la humanidad el cristianismo puro y primitivo ${ }^{14}$. Otra indisputable muestra, por si fuera necesario, de que, a semejanza de muchos liberales españoles, por muy anticlerical que es nuestro autor, no es un descreído.

Su falta de entusiasmo por la filosofía de las Luces le viene dictada por lo que se derivó de la aplicación de sus teorías, a saber, la Revolución francesa. Efectivamente, Francia, gran nación, instauró el sistema de «gobierno sin privilegio» que la filosofía dieciochesca presentaba como tierra de promisión. Pero esta revolución acarreó grandes sufrimientos. No obstante, Escudero echa en gran parte la culpa al clero, quien hubiera debido admitir los nuevos principios, ya que en el fondo no eran sino una versión renovada de las máximas evangélicas de igualdad y ley para todos. Del mismo modo, lamenta que la nobleza haya rechazado tajantemente en 1789 lo que aceptó en 1830, así se hubiera podido introducir el nuevo

12. Escudero, Antonio, op. cit., p. 7.

13. Ibid.

14. «Esta filosofía, en medio de su tono pretencioso, dogmático, y en mucha parte falto de exactitud, proclama verdades eternas en politica y en moral; verdades que ya habia proclamado el cristianismo puro y primitivo en su cuna». Ibid. 
orden de cosas evitando las catástrofes que la humanidad tuvo que deplorar ${ }^{15}$. Desde luego, es patente que nuestro autor está ahora barriendo hacia dentro: haciendo caso omiso de que un sector de la nobleza francesa -los legitimistas, fieles a los Borbones-, se negó a reconocer el régimen sedicente «burgués» auspiciado por el primo de éstos, Luis Felipe de Orléans; en puridad, Escudero aboga por el proceso que se está llevando a cabo en su propio país, donde la implantación del liberalismo fue el fruto de un convenio entre la burguesía y la parte «moderna» de la nobleza contra el carlismo arcaizante.

Luego, reanudando con el hilo de su resumen de la Historia de España, nuestro ensayista vitupera a los sucesores austriacos de Felipe II quienes, por ser estúpidos, entregaron el reino a la milicia de Roma. En cuanto al primer Borbón, Felipe de Anjou, no fue capaz de «sacar a la nación de la huella monacal» ${ }^{16}$-en contra de lo que cabía esperar, dada la acérrima política regalista llevada en Francia por su abuelo Luis XIV-. En definitiva, Felipe V no hizo más que transigir con los frailes y la Inquisición. Y, al fin y al cabo, lo único que sacó el país fueron los pactos de familia, que lo dejaron a remolque de las vicisitudes de la política gala ${ }^{17}$. Por ende, a cambio de distribuir la sopa boba a los proletarios -nótese el empleo novedoso de este sustantivo bajo la pluma de Escudero ${ }^{18}$-, el clero siguió desollando al pueblo, prohibiendo el uso de la razón e impidiendo la difusión de los libros extranjeros que favorecieran «la marcha y progresos del entendimiento humano» ${ }^{19}$. Escudero suaviza, pues, sus anteriores críticas a la filosofía de las Luces, tributando un homenaje implícito a dos obras clave de esta corriente intelectual, como son las de Locke y Condorcet. Más adelante, continúa fustigando a los reyes quienes, dejándose engatusar por la Iglesia que los proclamaba monarcas de derecho divino para mejor tenerlos en su mano, llevaban una existencia lujosa e indolente, sin manifestar interés alguno por el gobierno de su vasto imperio. Claro que algún ministro, generalmente de origen popular y en especial bajo el reinado de Carlos III, procuró sacar al país de ese letargo mortífero, no obstante sus tentativas se desbarataron «al pie del muro de bronce, en que Roma y sus satélites tenían aprisionado el genio español» ${ }^{20}$.

A principios del Ochocientos, una tormenta vino a sacudir el «silencio sepulcral y el aire mefítico» de España: Napoleón usurpó, mediante la doblez y la

15. Ibid., p. 8

16. Ibid., p. 9 .

17. Ibid.

18. Fernández Sebastián, Javier y Fuentes Aragonés, Juan Francisco, Diccionario político y social del siglo XIX español, Madrid, Alianza Editorial, 2002, p. 167.

19. ESCUDERo, Antonio, op. cit.

20. Ibid. 
violencia, la corona mal asentada en las sienes de Fernando VII. Y, a la pusilanimidad del Borbón, que se mostró incapaz de dar la cara al Emperador, Escudero contrapone, con fogoso y sincero patriotismo, la inmensa valentía y el ardor guerrero del pueblo ${ }^{21}$. Por consiguiente, lo que llevó a los españoles a empuñar las armas fue el anhelo de defender el honor nacional. Y en esta intrépida empresa se unieron todos: el pueblo bajo se movilizó en nombre de su rey y de «lo que llamaba su religión»-que, según insiste nuestro autor, no era sino el «establecimiento monacal $\gg^{22}$. En lo que respecta a la clase media, más culta y conocedora de las hazañas militares de los siglos XV y XVI, no admitió el ultraje perpetrado a «una tierra que consideraba como la patria natural del heroísmo» $»^{23}$. Por cierto, nuestro ensayista tiene que reconocer que algunos cortesanos, políticos o pensadores, creyeron imposible resistir o se imaginaron que, bajo los auspicios de la potencia napoleónica, España escaparía de su embrutecimiento, pero estos espíritus débiles y extraviados fueron muy contados y, a la postre, fue la voluntad de la nación la que triunfó como la del hombre más poderoso del planeta desde César ${ }^{24}$.

Mientras España libraba este desigual y épico combate contra el opresor extranjero, unos cuantos hombres, «animados de un buen deseo» ${ }^{25}$, acordaron reformar las instituciones gubernamentales para que los destinos del país ya no estuviesen a la merced del capricho de un príncipe que, como Carlos IV, había rebajado la majestad del trono a nivel de pasiones miserables o que, como Fernando VII, había abandonado a su pueblo en las garras del invasor. Para ello, elaboraron una ley fundamental en la que se consignaron los derechos y los deberes del Gobierno y del pueblo ${ }^{26}$. En opinión de Escudero, esta Constitución de Cádiz no carecía de defectos -pecaba señaladamente por restringir en extremo el poder del monarca y por «su exuberancia de teorías filosóficas» ${ }^{27}$, que no tenían cabida en semejante Código- pero esos fallos eran nimiedades que habían de enmendarse con el tiempo. Lo esencial era que proclamaba la soberanía nacional y abría paso a la «regeneración $»^{28}$. Dicho concepto había surgido en el escenario

21. «... pero un pueblo, que se acordaba de que Francisco I había sido su prisionero en el Alcázar de Madrid y que la Europa temblaba en presencia de los viejos tercios de Castilla, no podía ser tratado como el principado de un círculo de Alemania o de los débiles Estados de la Italia». Ibid., p. 10.

22. Ibid.

23. Ibid.

24. Ibid.

25. Ibid., p. 12.

26. Ibid.

27. Ibid.

28. «Su proclamación [de la Constitución de Cádiz] fue un paso inmenso en la carrera de regeneración que iba a abrirse en España; su existencia aseguraba el principio de la Soberanía nacional, fuente de todos los poderes». Ibid. 
político durante la Revolución francesa y también estaba en voga en España, dado que Napoleón ya se había erigido, en 1808, en el «regenerador» de la monarquía hispana para tratar de legitimar el cambio dinástico y para seducir a los españoles, prometiéndoles remediar los males que padecía su patria. Por eso, la voz «regeneración» fue entonces mucho más utilizada por los josefinos que por los liberales gaditanos, antes de que el liberalismo la hiciera suya durante el Trienio liberal. Un concepto, por demás, que, como sabemos, tendría, en adelante, mucho porvenir en España.

Para Escudero, los dos principales logros de la Carta Magna de 1812 consistieron en acabar con el «principio del privilegio y dar guerra a muerte al principio monacal $\aleph^{29}$, expresión de la que se vale para estigmatizar al conjunto del clero, tanto regular como secular. Y, a la hora de examinar cómo fue recibido este nuevo pacto por la sociedad española, expone una visión algo distorsionada de la Historia reciente de su país. Afirma, con razón, que la clase media urbana, aprobó el cambio, por cuanto cifró en él sus esperanzas de fomento económico así como de reparto más igualitario de las riquezas y de los tributos, gracias a una forma de gobierno más racional ${ }^{30}$. Del mismo modo, todo aquél que se dedicaba a pensar se entusiasmó por las doctrinas liberales, porque éstas traían consigo la libre difusión de las ideas y porque la Constitución no hacía más que restaurar las tradiciones democráticas de la nación ${ }^{31}$. En lo tocante a la plebe-palabra sumamente despectiva, y, con todo, nada inusual bajo la pluma de un liberal tibio-, asegura que dichas clases populares, acostumbradas a obedecer a las autoridades, aceptaron el nuevo Código con agrado, o por lo menos sin manifestar hostilidad en su contra ${ }^{32}$. Empero, Escudero también aduce que los nobles vieron con muy buenos ojos las transformaciones en la organización política del país, por cuanto habían tocado con el dedo la corrupción de la Corte, habían sido humillados por el valido Godoy y, como grandes propietarios que eran, resultaban lesionados por el abandono en que se hallaba la agricultura. De ahí que, a diferencia de la nobleza francesa, que se había opuesto sañudamente a las reformas, la de España se adhiriera al liberalismo ${ }^{33}$. Y pasó lo mismo con la oficialidad que, por leer la

29. Escudero, Antonio, op. cit., p. 13.

30. Ibid.

31. «Por otra parte, los ejemplos de mejor administración en otros países eran demasiado palpables y desde que, de pocos años a esta parte, habian sido rotas las barreras que impedian la introducción de escritos y libros extranjeros, esta circulación y la prensa libre habian hecho una fuerte impresión en los ánimos de la clase que pensaba; a lo que se agrega la popularidad que proporcionaba al nuevo código la idea bastante generalizada de que él no era más que la renovación de las antiguas libertades de la nación». Ibid., pp. 13-14.

32. Ibid., p. 14.

33. Ibid. 
literatura francesa, estaba embebida en las ideas nuevas ${ }^{34}$. Nuestro autor parece, pues, ilusionarse con la actitud de la nobleza y del ejército. Si bien es irrebatible que algunos nobles fueron liberales convencidos y sinceros e, incluso, colaboraron en la instauración del nuevo régimen, pretender que fue el caso del conjunto o de la mayoría del estamento sería tergiversar la realidad. Si Fernando VII pudo, en 1814, dar un golpe de Estado que lo restableció como «rey neto», fue en gran parte porque contó con el respaldo de la nobleza absolutista, encabezada por el duque del Infantado. Y también conviene matizar la conducta de los oficiales durante la Guerra de la Independencia: una minoría de ellos, esencialmente la oficialidad joven y de origen plebeyo, militó en las filas del liberalismo -y bien se sabe que formaría la punta de lanza de la segunda etapa liberal, que se abrió en 1820-, no obstante, casi todos los militares que pertenecían a la nobleza de vieja cepa permanecieron fieles a la monarquía absoluta.

En puridad, Escudero no es tan ingenuo como se podría sopechar. Si exagera la reacción positiva de los distintos sectores sociales ante la revolución liberal, es para mejor agobiar a los clérigos que, a su parecer, fueron los únicos en rechazar el nuevo sistema. Le declararon en el acto una guerra sin cuartel, aunque empezaron pugnando de forma cauta, contentándose con ejercer una oposición legal, para no desentonar con la unánime aceptación de la nación:

«El principio monacal, sin embargo, no podía ver las cosas del mismo modo, pero al notar la uniformidad de las demás clases en aceptar el nuevo régimen político, sólo se limitó a hacer una oposición legal, por medio de la prensa y de la tribuna pública, hasta que llegase el tiempo de descubrir otra clase de baterías» ${ }^{35}$.

A continuación, nuestro ensayista se alegra de que las Cortes de 1812 tuvieran la cordura de no deponer a Fernando VII, como quiera que su nombre era un talismán para el pueblo bajo y éste, manipulado por la Iglesia frailuna, se hubiera levantado contra las nuevas autoridades. Pero donde sí se cometió un error garrafal fue encomiando a porfía al monarca ausente, convirtiéndole en un verdadero ídolo, lo que, después, les costó muy caro a los liberales ${ }^{36}$. Así, Fernando, quien en realidad carecía por completo de las dotes necesarias para ser un soberano digno, sacó partido de la leyenda áurea que se había fraguado en torno a su real persona, para destrozar toda la obra reformadora de las Cortes y perseguir sin piedad a quienes habían salvado a la nación. Y todos estos males se debieron, antes que nada, al desastroso influjo que el «principio monacal» ejercía en ese rey débil, que se dejaba manejar por una clerecía que, conculcando su

34. Ibid.

35. Ibid.

36. Ibid. p. 15.

Pasado y Memoria. Revista de Historia Contemporánea, 8, 2009, pp. 161-179 
misión sacra, atizó el odio y excitó los deseos de venganza, en lugar de predicar la paz y la reconciliación ${ }^{37}$.

Sin embargo, un Gobierno que tiraniza a un pueblo no cobarde, no puede mantenerse mucho tiempo y la «clase pensadora», que se había incrementado notoriamente desde 1808, se organizó dentro de sociedades secretas. Así, las múltiples conspiraciones que se urdieron entre 1814 y 1820 pusieron de manifiesto que el sistema estaba «volcanizado» ${ }^{38}$. De ahí, según Escudero, el triunfo inmediato y fácil de Riego y de los militares liberales que se pronunciaron en Las Cabezas de San Juan ${ }^{39}$-aunque, en rigor, dicha victoria de la revolución no fue ni tan rápida ni tan sencilla ${ }^{40}$ -

Lo que quiere recalcar Escudero es que, en el espacio de 12 años, se produjeron, en el terreno político, nada menos que tres intervenciones del ejército y que cada una de ellas causó un cambio de rumbo drástico en el Gobierno. Desde su óptica, la primera de estas rebeliones militares fue el motín de Aranjuez, ingeniado contra Godoy por un clero ultrajado por la desamortización que había iniciado el valido, de consuno con una aristocracia eclipsada por el advenedizo y que «sufría el martirio ante el lujo asiático» de éste y ante la adoración que los reyes profesaban al «visir» ${ }^{41}$. De este modo, se dio un «colorido honesto» a la insurección de unos guardias de corps que, en el fondo, fue maquinada por el «principio monacal» ${ }^{42}$. Y la rabia anticlerical de Escudero lo lleva ahora a reconocer que, a pesar de los pesares y de su vida disoluta, el Príncipe de la Paz fue un ilustrado que protegió a algunos literatos y humanistas y, sobre todo, tuvo el señalado mérito de procurar recortar el influjo del estamento eclesiástico ${ }^{43}$. A los

37. «Un rey cuya educación había sido descuidada, quizá a intento corrompida, que había dado, desde la insurrección contra su padre, desde el abandono de la España contra el voto universal y bien claramente manifestado de la nación, desde su cautiverio en Valençay, pruebas nada equivocas de no reparar mucho en los medios para obtener el poder, de no tener la energía ni los sentimientos de la dignidad nacional que más deben brillar en un monarca... apenas pisó el suelo español, derribó todo lo que la revolución había edificado... Las persecuciones, los presidios, los destierros con que se premiaron a los que habían contribuido a salvar la nacionalidad española, las predicaciones furibundas de los que se anunciaban siempre como ministros de la religión del que murió por el género humano, en fin, la reacción espantosa que dominó en todo este cuadro, debieron probar si el principio monacal se dejaría impunemente despojar de su presa y si él tenía un instrumento bien dispuesto en el que ceñía la corona». Ibid., pp. 15-16.

38. Ibid., p. 16.

39. «La oficialidad se conjura; al soldado se le persuade fácilmente; la revolución estalla. La constitución de 1812, proclamada desde luego por el ejército expedicionario, lo es en seguida por la mayor parte de las provincias». Ibid., p. 17.

40. Gil Novales, Alberto, El Trienio liberal, Madrid, Siglo XXI, 1980, p. 4.

41. Escudero, Antonio, op. cit., p. 18.

42. Ibid., p. 19.

43. Ibid., pp. 18-19.

Pasado y Memoria. Revista de Historia Contemporánea, 8, 2009, pp. 161-179 
ojos de nuestro «historiador», el nexo de unión entre dicho motín de Aranjuez y la segunda «manifestación militar»-el alzamiento del general Elío en Valencia en 1814 para restablecer al Borbón como monarca absoluto-, fue que ésta también la dirigió la «mano monacal» que, después, tanto se benefició del golpe de fuerza ${ }^{44}$.

Obviamente, le resulta imposible a nuestro ensayista -o mejor cabría llamarle «libelista» por el encarnizamiento con que asalta a la Iglesia- implicar al clero en la tercera sublevación militar, la de 1820, que abrió paso al renacer del sistema liberal. A su juicio, el éxito se debió a que las doctrinas liberales habían captado entonces a toda la parte activa y pensadora de la nación y a que «las legiones monacales» no se atrevieron a reaccionar de entrada, sino que aparentaron una «muda indiferencia» ${ }^{45}$. Para demostrar cuán impresionado tenían que ser entonces los sacerdotes por la expansión de las ideas innovadoras, Escudero pinta un cuadro muy halagüeño, por no decir excesivamente optimista, de la adhesión de los españoles a estas nuevas teorías. La clase «decente» tenía como lectura predilecta los libros de «los Montesquieu, Rousseau, Voltaire, los enciclopedistas, los Raynal, los Mably, los Destutt-Tracy y las traducciones francesas de Smith, en el tratado de Say» ${ }^{46}$, que le sirvieron de maestros. Por su parte, los oficiales, entre los cuales muchos habían descubierto el pensamiento de los filósofos franceses durante su cautiverio en los años de la Guerra de la Independencia, veían con despecho, cómo el Gobierno fernandino descuidaba sus intereses en provecho de los frailes ${ }^{47}$. En cuanto a la clase industrial, quedaba arruinada por la equivocada política bélica llevada contra las colonias americanas ${ }^{48}$. En resumen, toda la España «inteligente» se daba cuenta de que era imprescindible cambiar

44. Ibid., pp. 19-20.

45. Ibid., p. 21.

46. Ibid., pp. 22-23.

47. «La oficialidad que mandaba el ejército se componía de hombres que habían peleado por la independencia nacional y, muchos de ellos habian regresado de su estado de detención como prisioneros en Francia: a casi todos era común el conocimiento del idioma francés y, si nadie ignora el influjo que la literatura ejerce sobre las opiniones y recuerda que los filósofos del siglo XVIII eran la lectura favorita de todo hombre que quería saber algo (y esta pasión se hizo general entonces entre la clase decente en España), fácilmente supondrá el modo de pensar de los militares en materia de gobierno y de progreso; agréguese a esto la idea que había cundido entre ellos de lo desairado que era el nombre español en el extranjero, en donde España y pueblo de frailes eran sinónimos. Pues bien, con estas opiniones, los intereses de los militares eran descuidados, desatendidos en favor de los mismos frailes objeto de su desprecio; en una palabra, no era difícil ver a un militar, cuyas heridas recibidas defendiendo el país apenas estaban cicatrizadas, pedir limosna a la inmediación de un convento, que se reconstruía con la magnificencia de un alcázar, o que se decoraba con la pompa de una basílica». Ibid., p. 22.

48. «Por otra parte, la industria nacional, que apenas tenía otra exportación que a la América española para sus productos, se veía abatida y arruinada, perdiendo hasta la esperanza en el

Pasado y Memoria. Revista de Historia Contemporánea, 8, 2009, pp. 161-179 
de rumbo y acabar con el «principio monacal» ${ }^{49}$. Por lo mismo, se restableció la Constitución de Cádiz «con la rapidez de la electricidad en todo el reino» y, máxime porque, entonces, el "partido liberal estaba unido» ${ }^{50}$. Si Escudero subraya las consecuencias positivas de la unión en 1820 es para exhortar indirectamente a los liberales a hacer ahora causa común en torno a la nueva Carta Magna, la de 1837, unión sin la cual no podrán vencer el carlismo.

Empero, paradójicamente, mientras aboga por la reconciliación, nuestro autor no se arredra por hacer gala de un ideario conservador, que difícilmente podían compartir los liberales más avanzados. Repite sus reticencias acerca del Código gaditano. Por cierto, supuso el ingente aporte de eliminar el derecho divino como legitimación del poder y de sustituirlo por el principio de la soberanía nacional:

«[La Constitución de 1812] contenía una verdad aplicable a todos los pueblos que quieren con energía salir de la rutina de un gobierno de privilegio, esto es, el principio del origen del poder, la Nación; principio contrapuesto al de derecho divino». ${ }^{51}$

Sin embargo, adolecía de un parentesco demasiado estrecho con el pacto social de Rousseau, que «engendró la constitución del año 1791 para un pueblo vecino» ${ }^{52}$. Dicho de otro modo, era una obra de circunstancias, que no se adecuaba a la sociedad española. Por consiguiente, si el régimen liberal no fuera torpedeado desde 1820 por el Borbón y agredido después por los reaccionarios, con el auxilio del «gobierno retrógrado de Luis XVIII»" s3 $^{3}$ la Constitución de Cádiz no se hubiera granjeado tanto prestigio y hubiera dejado paso, de forma natural, a otro texto fundamental, más en sintonía con la idiosincracia de España:

«La Constitución de Cádiz hubiera pasado, ella hubiera concluido su misión revolucionaria, dejando el puesto a otra más apropiada a las necesidades reorganizadoras del país, que se hubiera hecho lugar por la misma fuerza de las cosas». ${ }^{54}$

Según nuestro ensayista, la principal lacra de la «Pepa» consistió en que no acertó a crear «el mayor número de intereses nuevos, conservando el mayor número de intereses antiguos posibles», lo que ha de ser el objetivo de toda revolución ${ }^{55}$. Huelga decir que semejante concepción es propia del reformismo y tiene poco

porvenir, si las poblaciones de las nuevas repúblicas se acostumbraban a otros consumos». Ibid. p. 23.

49. Ibid. pp. 23-24.

50. Ibid. p. 24.

51. Ibid.

52. Ibid.

53. Ibid. p. 25.

54. Ibid.

55. Ibid., p. 26. 
que ver con la ideología revolucionaria, cuya meta es, en principio, hacer tabla rasa del pasado. Desde esta perspectiva, Escudero deplora que los liberales hayan prescindido del talento de los ex afrancesados y hayan marginado a estos «auxiliares apetecibles contra el principio monacal», recelando erróneamente de ellos, lo que disuadió a muchos de respaldar decididamente la lidia contra ese consabido peligro clerical $^{56}$. Peor todavía, las primeras reformas dictadas por las Cortes sembraron la discordia entre los liberales, lo cual desembocó en la creación de las sociedades secretas, a las que nuestro ensayista tilda ahora de «otra de las plagas de la revolución española» ${ }^{57}$. A sus ojos, éstas pueden ser útiles bajo un gobierno despótico, en cambio, su existencia no se justifica en un régimen democrático, en el que cada ciudadano goza de la plena libertad de expresar sus opiniones mediante la prensa o la tribuna pública. Más aún, su labor «subterránea» las hace dañinas y Escudero culpa a los masones, comuneros y anilleros de haber socavado el liberalismo ${ }^{58}$. En buena lógica, esa desastrosa división del bando constitucional dejó campo libre al servilismo. No obstante, como los contrarrevolucionarios fracasaron -y de forma estrepitosa el 7 de julio de 1822-, tuvieron que acudir a la Santa Alianza, la cual encomendó al Gobierno de Luis XVIII la «misión poco gloriosa de llevar las cadenas a un pueblo que quería ser libre» ${ }^{59}$. Y, a sabiendas de que los Cien Mil Hijos de San Luis tropezarían con una resistencia empecinada, se echó mano de la astucia, procurando convencer a los españoles de que el duque de Angulema venía a establecer una monarquía constitucional moderada, copiada del modelo francés ${ }^{60}$. Escudero ataca de falsedad los argumentos de los absolutistas, luego recogidos por la historiografía tradicionalista, según los cuales, a partir de 1822, la mayoría del pueblo era muy

56. «Este partido conocido por el nombre de «afrancesados» contaba en sus filas hombres de talentos superiores que, en la nueva lucha contra el principio monacal, eran auxiliares apetecibles... Por otra parte, estos hombres como partido político no podían de ningún modo inspirar recelos, pues el árbol, de que ellos eran una ramificación bien tenue, habia sido cortado en la raíz. Pues bien, a estos hombres se los excluyó del movimiento social que se ensayaba; y varios de ellos, no pudiendo hacerse superiores a este desaire, miraron siempre después con desapego la forma política que habia adoptado la opinión liberal por su bandera, y fueron el núcleo de una secta politica que ha seducido a mucho hombre de bien por lo atractivo de sus teorías, y ha embarazado el desarrollo enérgico de la revolución contra el principio monacal». Ibid., p. 27.

57. Ibid., p. 28.

58. «En efecto, la utilidad de este taller, que forja sus armas en la oscuridad, puede concebirse con la coexistencia de un gobierno despótico, cuyo terreno es menester minar; pero desde que la razón tiene por la prensa y la tribuna pública medios de hacer oír su voz a la luz del día, la permanencia de estos trabajos subterráneos es una anomalía, un anacronismo, un peligro. ¿Y quién dudará de lo que debilitó (sic) a los liberales las animosidades de los comuneros, masones, anilleros, etc.?». Ibid.

59. Ibid., p. 30.

60. Ibid., p. 31.

Pasado y Memoria. Revista de Historia Contemporánea, 8, 2009, pp. 161-179 
hostil al liberalismo y aclamó al ejército francés, vitoreando a la Inquisición y al rey absoluto ${ }^{61}$. Empero, cabe mitigar sus acusaciones a los gobernantes galos. $\mathrm{Si}$ bien no cabe duda alguna de que éstos deseaban poner término a la «revolución» española, tampoco eran proclives a que el Borbón español siguiera tiranizando a sus súbditos y aspiraron, en vano, a la implantación de un sistema constitucional muy templado, similar al suyo ${ }^{62}$.

Más adelante, Escudero destaca cuán cruentas fueron las represalias y las persecuciones tras la liquidación del Trienio liberal, pero admite que Fernando VII aplacó un tanto las pasiones reaccionarias, por «instinto de conservación», porque se percató de que éstas llevaban al país a la ruina y a la despoblación ${ }^{63}$. No se restauró la Inquisición y el Rey procuró librarse del dominio de la «Teocracia», pero ésta tomó entonces partido a favor de su hermano Carlos y orquestó el alzamiento de los Agraviados para aleccionar al monarca imprudente ${ }^{64}$. Por ende, ya fallecido Fernando, reanudó con más furor su lucha por seguir avasallando a España y el problema sucesorio sólo sirvió de pretexto:

«En vano, los que miraban sólo la superficie de las cosas se hicieron la ilusión de creer que la cuestión política se limitaría al estrecho círculo de la sucesión a la corona... Pero la cuestión principal no estaba ahí: lo que se trataba de saber era si el principio que había dominado por tantos siglos y reducido a la España a la inanición en que estaba, habia de permitir que otras influencias que las suyas ondeasen sobre el trono». ${ }^{65}$

En puridad, la legitimidad de la reina niña ni se puede cuestionar, dado que se cumplieron todos los requisitos legales para abrogar la ley sálica, y la guerra es, en exclusiva, culpa del «principio monacal» que se empeña en apoyar a un príncipe fanático, en aras del derecho divino, frente a Isabel, que reina por la «voluntad nacional». Si todos los liberales -el subrayado es de Escudero- hubiesen entendido enseguida que éste era el verdadero envite, la Constitución de 1837, que garantiza la corona a Isabel y su descendencia, se hubiera promulgado mucho antes y don Carlos ni siquiera hubiera ingresado en España ${ }^{66}$. Por desgracia, cuando principió la contienda, el liberalismo carecía todavía de cimientos sólidos y sólo se fue consolidando gracias al buen tino y a la generosidad de la regente María Cristina. Estas cualidades le permitieron conseguir el apoyo de muchos realistas, que fueron influenciados por la Revolución francesa de 1830

61. Ibid., p. 32; véase también La ParRa López, Emilio, Los Cien Mil Hijos de San Luis. El ocaso del primer impulso liberal en España, Madrid, Síntesis, 2007, p. 119 y ss.

62. Ibid., pp. 108-117.

63. EsCudero, Antonio, op. cit., p. 36.

64. Ibid., pp. 36-37.

65. Ibid., pp. 38-39.

66. Ibid. 
y que, a partir de entonces, militaron en las filas del moderantismo, aceptando con cautela las doctrinas liberales, con tal que se respetaran las prerrogativas regias $^{67}$. Pero estos neófitos del liberalismo, que eran antiguos afrancesados, grandes propietarios, notables y militares de alta graduación, sentían más interés por el progreso material que por las teorías políticas. Por eso, desconfiaban de la obra de los «soñadores» que habían iniciado la revolución, a saber la Constitución de Cádiz, un pacto impracticable para una nación tan atrasada como España ${ }^{68}$. El segundo escollo que estorbó la unión de los liberales fue la desdichada costumbre de contemplar los alborotos a la luz de la Revolución francesa. Una vez más, en 1836, muchos temieron que el motín de la Granja degenerara en un atentado a la monarquía y en su sustitución por una república, una cosa inconcebible en España, donde las convulsiones nunca acarrean desacato al Rey ${ }^{69}$.

Afortunadamente, ha tocado ya la hora de superar las desavenencias entre las dos partes de la «España progresiva»: por un lado, los hombres de 1834 quienes, precisamente por miedo a los tumultos, fueron partidarios del Estatuto Real, o sea de un mero retoque a la institución monárquica, apostando así por una especie de revivir del Despotismo ilustrado, y por otro lado los hombres de 1812, que propugnan la plena aplicación del principio de soberanía nacional. Y la solución reside en el nuevo texto constitucional ${ }^{70}$. Esta Carta Magna de 1837 puede agradar tanto a los defensores de la soberanía de la nación, ya que ha sido «decretada y sancionada» por las Cortes Constituyentes, como a aquéllos que desean que la Corona disfrute de un auténtico poder. De hecho, a tenor del nuevo código, el Rey compartía la facultad de hacer las leyes con las Cortes, las sancionaba y promulgaba, amén de nombrar y despedir libremente al Gobierno. Asimismo, señala nuestro ensayista, los intereses de las clases pudientes serán resguardados por el Senado y por el sufragio censitario, al paso que la nueva ley electoral también facilita el acceso al Congreso de los Diputados a la «inteligencia»y al «trabajo», que será representado por la «pequeña propiedad, su consorte» ${ }^{71}$. Escudero le otorga, pues, al sistema de 1837 una índole democrática

67. «Tras la revolución francesa de 1830, que tanto impulso ha dado a la nuestra..., se formó la secta de los realistas moderados; hombres que admitían los principios liberales como teoría, pero sólo reconocían como practicables las consecuencias en materia de gobierno, en cuanto compatibles con la voluntad del príncipe». Ibid., p. 42.

68. Ibid., p. 43.

69. Ibid., pp. 41 y 46.

70. Ibid., pp. 49-50.

71. «Todas las ramificaciones del partido liberal tienen aquí de qué satisfacer sus deseos, sus intereses: los amantes imperturbables de la consagración integra del principio que se substituye al monacal, la ven conseguida, pues la Constitución ha sido «decretada y sancionada» por las Cortes constituyentes de la nación, y aceptada por la reina; los que querían ver revestido el poder real de 
que distaba mucho de tener: recordemos que, por cierto, se amplió el electorado con respecto a 1834, pero, aún así, únicamente el 2,2\% de los varones españoles podían elegir a sus representantes en la Cámara baja. Además, nuestro autor no ostenta un sentido muy exacerbado de la democracia. A su parecer, en cuanto se realice la indispensable reconciliación entre los liberales y queden abatidos don Carlos y el «principio monacal», el «espíritu liberal reorganizador» ${ }^{72}$ tendrá campo libre. Y entonces llama la atención lo que preconiza: es todo un catálogo de medidas administrativas, que abarcan desde la construcción de carreteras y canales hasta la elaboración de una red de instrucción pública, pasando por la uniformización de la moneda:

«Los hombres verdaderamente ilustrados vendrán a ocuparse de tantas reformas como la España necesita; mejoras en la administración; economías en los gastos; arreglo del laberinto de la hacienda pública; formación de códigos; leyes de aranceles para quitar trabas a la industria... construcción de caminos y canales, que aproximen a los habitantes de las provincias, robusteciendo asi una nacionalidad tan dividida como la nuestra, al paso que dieran un impulso increible a las fuentes de riqueza; uniformar los pesos, medidas y monedas por la adopción del sistema decimal; fundar un plan de instrucción pública que tanto necesitamos; he aqui objetos que ocuparán probablemente su atención». ${ }^{73}$

En resumen, un programa que remite a los proyectos ya esbozados unos setenta años antes, en la época del Despotismo ilustrado, mientras que las reformas sociales brillan por su ausencia. Pero no hacen falta, pues Escudero está convencido de que el reformismo que promueve traerá mecánicamente -o quizá por arte de magia- el bienestar a sus conciudadanos y deparará a su país la grandeza a la que le destina la Providencia ${ }^{74}$.

A la hora de concluir su Ensayo..., Escudero riza el rizo, reiterando su llamada a los «gobiernos ilustrados» extranjeros, que deben entender cuán perjudicial resultaría también para ellos el triunfo del carlismo, puesto que originaría un «foco de combustión» en Europa ${ }^{75}$. Esta vez añade un argumento de tipo económico: los países vecinos tienen interés en sostener la causa cristina por cuanto, con el liberalismo y la prosperidad que sólo éste puede generar al sur del Pirineo,

fuerza y de prestigio, tienen cómo complacerse en las saludables garantías dadas a la acción de la corona; la propiedad ve sus intereses garantidos por el Senado y por el bastante alto censo de su elegibilidad; la inteligencia tiene las puertas abiertas con las facilidades que le dan para optar a la diputación; el trabajo está representado por la pequeña propiedad, su consorte, para quien la entrada al Congreso de los Diputados es tan accesible». Ibid., p. 50.

72. Ibid., pp. 52-53.

73. Ibid., p. 52.

74. Ibid.

75. Ibid., p. 54. 
acrecentarán sus intercambios con España ${ }^{76}$. En fin, nuestro autor no se priva de disparar una última flecha a su blanco predilecto, advirtiendo a sus compatriotas que, para ingresar en el círculo selecto de las naciones civilizadas, deben aniquilar «el genio de Torquemada» ${ }^{77}$.

Este Ensayo sobre las opiniones políticas.... constituye, pues, una cabal prueba más de que, a partir del Trienio constitucional, se generalizó y agudizó el anticlericalismo entre los liberales ${ }^{78}$. Más aún, como ha recalcado Antonio Moliner Prada, durante la Primera Guerra Carlista se exacerbó la animadversión mutua, conforme fue creciendo el número de eclesiásticos que se decantaron a favor del pretendiente, como reacción a la política cada vez más radical del liberalismo contra la Iglesia $^{79}$. Por ende, si no pocos clérigos abrazaron la causa del carlismo integrista por afán de preservar sus privilegios y de mantener el dominio que ejercían en la sociedad española ${ }^{80}$, cabría preguntarse, al leer el texto de Escudero, si, en el campo opuesto, no fue ante todo un anticlericalismo visceral lo que empujó a unos liberales tibios a respaldar el nuevo régimen.

Por lo tanto, la muy vengativa acometida de nuestro autor a los tonsurados también sirve para justificar la política religiosa emprendida por los liberales. De hecho, la actitud del clero carlista que garantizó la cohesión ideológica de los facciosos, predicando en pro del absolutismo y del mantenimiento de una estrecha alianza entre el Trono y el Altar ${ }^{81}$, propició los embates de las nuevas autoridades contra el conjunto del estamento, en un contexto en que, desde la Guerra de la Independencia, se había empañado la imagen de éste, debido al cambiazo de muchos pastores quienes, después de hacer alarde de patriotismo en 1808, huyeron abandonando a su grey conforme avanzaban la tropas

76. Ibid.

77. «En fin, no hay español con sangre en las venas y que no esté cegado por la pasión o sumido en la ignorancia, que no sienta que con la vecindad de dos grandes naciones gobernadas constitucionalmente, la España actual pueda serlo por el genio de Torquemada. Recordemos que los países no son felices sino por sus propios esfuerzos (el subrayado es de Escudero) y que su ventura está librada a la reunión de sus hijos, en un centro común de nacionalidad y de progreso iQuiera el cielo que este momento haya llegado para España!». Ibid., p. 55.

78. La Parra López, Emilio, «Los inicios del anticlericalismo español contemporáneo (17501833)», en El anticlericalismo español contemporáneo, Madrid, Biblioteca Nueva, 1998, p. 45.

79. Moliner Prada, Antonio, «Anticlericalismo y revolución liberal (1833-1874)», Ibid., p. 75.

80. Ibid., p. 71; véase también VAuchelle, Aline, «De la Guerra de la Independencia a las guerras carlistas, continuación del debate en torno a la utilidad de las órdenes religiosas en Diálogo entre Fray Pedro y Don Antonio», en Alberola, A., LarribA, E. (eds.), Las élites y la «Revolución de España» (1808-1814). Estudios en homenaje al profesor Gérard Dufour, Universidad de Alicante - Université de Provence - Casa de Velázquez, 2010, pp. 349-363.

81. Moliner Prada, Antonio, «Anticlericalismo y revolución liberal (1833-1874)», en El anticlericalismo español contemporáneo, Madrid, Biblioteca Nueva, 1998, p. 71. 
francesas y acabaron convirtiéndose en encarnizados enemigos de los patriotas liberales a partir de $1810^{82}$. Y, por si fuera poco, algunos sacerdotes no vacilaron en cantar la palinodia, protestando sucesivamente de su más sincera adhesión y fidelidad a José Bonaparte, a la Constitución de 1812 y a Fernando VII ${ }^{83}$. De modo que, a partir de 1834, los liberales no sólo reanudaron las reformas iniciadas en Cádiz y proseguidas durante el Trienio, sino que, esta vez, pudieron acelerarlas y profundizarlas, en un ambiente de alborotos populares, provocados por la guerra y sus secuelas económicas, que también presentaban una marcada vertiente anticlerical. A partir del mes de julio, se fueron multiplicando las masacres de frailes y los incendios de conventos, ya que el pueblo veía en ellos baluartes de la insurrección carlista, y porque ansiaba desquitarse del dominio secular de una Iglesia cuya opulencia ya no toleraba ${ }^{84}$. Con este telón de fondo, y aunque reprobaban esas rachas de violencia, los gobernantes tuvieron campo libre para tomar toda una panoplia de medidas encaminadas a reducir el caudal de la institución y a disminuir el número de eclesiásticos. Desde este enfoque, el ministerio encabezado por el moderado Conde de Toreno decretó, en julio de 1835, la expulsión de los jesuitas y la supresión de los conventos que contaran con menos de 12 profesos $^{85}$. En octubre del mismo año, estando los progresistas en el poder, con Mendizábal como presidente del Gobierno, se suprimeron todos los monasterios, con la salvedad de aquellos que pertenecían a las órdenes hospitalarias, lo que tuvo como consecuencia una reducción drástica del número de comunidades religiosas y el desmembramiento de sus tierras, que se vendieron, en concepto de bienes nacionales, para costear el esfuerzo bélico y sanear la situación de la Hacienda ${ }^{86}$. En marzo de 1836 se abolieron las cuatro órdenes militares y se clausuraron los colegios religiosos, así como todas las congregaciones, inclusive los conventos de monjas con menos de 20 religiosas $^{87}$. De esta forma, el nuevo Estado liberal destruyó uno de los principales puntales de la Iglesia del Antiguo Régimen, lo que le permitió, en adelante, sentar su autoridad en las instituciones caritativas y en la segunda enseñanza, hasta entonces controladas por el clero regular. Al mismo tiempo, se prohibió que los párrocos adictos al carlismo siguieran predicando y confesando a los fieles, privándoles así de rele-

82. La Parra López, Emilio, art. cit., p. 36.

83. Ibid.

84. Moliner Prada, Antonio, art. cit., pp. 78 y 86-93.

85. Ibid., p. 83.

86. Ibid., p. 95.

87. Ibid., p. 96. 
vantes medios de propaganda. Todas estas decisiones apuntaban a domesticar a la Iglesia y a subordinarla a los intereses del Estado ${ }^{88}$.

Después, con la formación del gabinete de Calatrava el 14 de agosto de 1836, consecutiva al motín de La Granja, se dio un nuevo empuje al combate contra los carlistas y, dentro de este marco, se procuró aniquilar el poder de nocividad de la clerecía partidaria del pretendiente. En enero de 1837 se otorgó a las autoridades civiles el derecho a fiscalizar los nombramientos de los sacerdotes y se pusieron bajo secuestro las rentas de los obispos que se hubieran ausentado de su diócesis por motivos políticos. En julio, ante el avance cada día más amenazador de las tropas de don Carlos hacia la Corte, se reactivó la política desamortizadora, dictando una ley que agilizó las exclaustraciones: unos 32.000 frailes y unas 15.000 monjas tuvieron que abandonar sus monasterios. Dicha ley afectaba asimismo al clero secular, dado que abolía el diezmo, aunque se aplazaba su aplicación hasta que el Estado pudiera sufragar el sostenimiento de los sacerdotes. Por último, en agosto se prohibió que los curas salieran de su parroquia sin permiso expreso del gobernador civil ${ }^{89}$. O sea, que a la Iglesia se le asestó un golpe durísimo: perdió sus ingresos fiscales y la mayor parte de sus bienes.

En pocas palabras, cuando salió a luz el Ensayo... de Escudero, todos los liberales, tanto los moderados como los más innovadores, coincidían por lo menos en que, para afianzar ideológica, económica y socialmente el constitucionalismo, era imperativo erradicar el oscurantismo, cuyos adalides más empedernidos eran los religiosos, al tiempo que resultaba inexcusable desmantelar el cuantioso patrimonio de la Iglesia para reestructurar a fondo la propiedad inmobiliaria. Y, por supuesto, la acérrima beligerencia de los clérigos carlistas sólo redundó en enconar su inquina anticlerical.

88. Ibid.; ver también Tortella Casares, Gabriel et alii, Revolución burguesa, oligarquía y constitucionalismo (1834-1923), Barcelona, Labor, 1990, p. 229.

89. Moliner Prada, Antonio, art. cit., p. 96. 